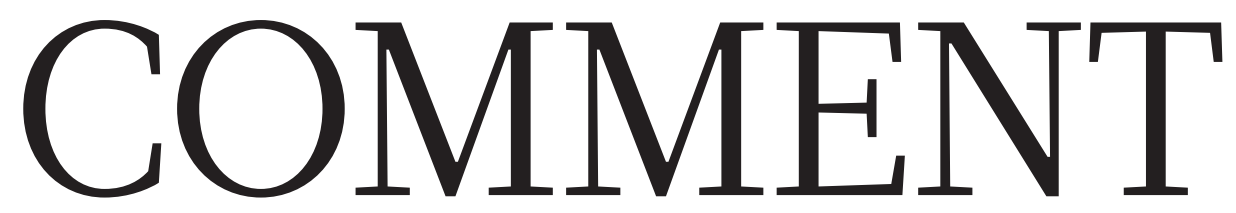

PHYSICS Reliable funding would bring back megascale US facilities p.522
PHILOSOPHY Why random events are often not unexpected in hindsight $\mathbf{p . 5 2 3}$
IN RETROSPECT Biochemist Alexander Oparin's treatise on life's beginnings p.524
CLIMATE CHANGE Protect

low-lying coastal cities from sea-level rise $\mathbf{p . 5 2 7}$

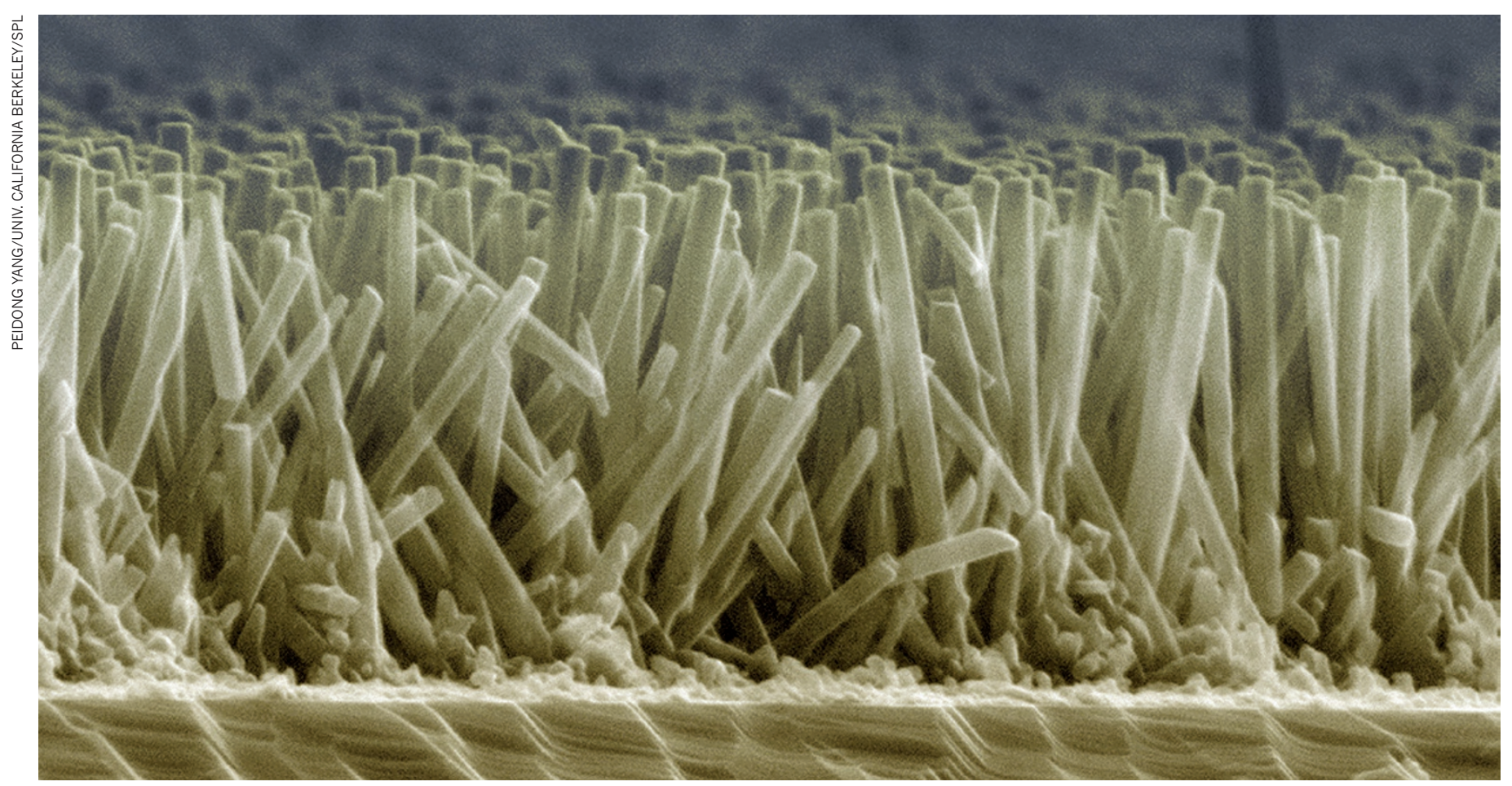

Artificially grown zinc oxide nanowires, as seen under a scanning electron microscope, measure only a few nanometres in diameter.

\title{
Make nanotechnology research open-source
}

\section{To drive innovation at the nanoscale, the patent thicket must be chopped down, argues Joshua M. Pearce.}

\begin{abstract}
A ny innovator wishing to work on or sell products based on singlewalled carbon nanotubes in the United States must wade through more than 1,600 US patents that mention them ${ }^{1}$. He or she must obtain a fistful of licences just to use this tubular form of naturally occurring graphite rolled from a one-atom-thick sheet. This is because many patents lay broad claims: one nanotube example covers "a composition of matter comprising at least about $99 \%$ by weight of single-wall carbon molecules". Tens of others make overlapping claims.

This thicket of patents, including entire
\end{abstract}

classes of nanotechnologies, basic methods and science, is hindering nanotechnology. Excessive patenting is increasing costs, slowing technical development and removing from the public domain fundamental knowledge about the understanding and control of matter on the atomic or molecular scale (1-100 nanometres).

Patent thickets occur in other high-tech fields, but the consequences for nanotechnology are dire because of the potential power $\checkmark$ NATURE.COM

More on the impact of nanotechnology investment:

go.nature.com/inicdx and immaturity of the field. Advances are being stifled at birth because downstream innovation almost always infringes some early broad patents. By contrast, computing, lasers and software grew up without overzealous patenting at the outset ${ }^{2}$.

Nanotechnology offers the promise of enabling matter to be manipulated as easily as software. I believe that those working with it should adopt the open-source approach $^{3}$ that has proved so successful for software development. All publicly funded nanotechnology research and innovation should be made available $>$ 
$\checkmark$ to everyone for free. A moratorium should be placed on patenting fundamental nanotechnologies and basic quantumscience applications, from which most developments stem.

\section{INTELLECTUAL-PROPERTY SHACKLES}

Nanotechnology is big business. According to a 2011 report by technology consultants Cientifica, governments around the world have invested more than US\$65 billion in nanotechnology in the past 11 years. The sector contributed more than $\$ 250$ billion to the global economy in 2009 and is expected to reach $\$ 2.4$ trillion a year by 2015, according to business analysts Lux Research. Since 2001, the United States has invested $\$ 18$ billion in the National Nanotechnology Initiative; the 2013 US federal budget will add $\$ 1.8$ billion more.

This investment is spurring intense patent filing by industry and academia. The number of nanotechnology patent applications to the US Patent and Trademark Office (USPTO) is rising each year and is projected to exceed 4,000 in 2012. Anyone who discovers a new and useful process, machine, manufacture or composition of matter, or any new and useful improvement thereof, may obtain a patent that prevents others from using that development unless they have the patent owner's permission.

With universities increasingly operating like corporations, faculty members are pressured into locking away their results as intellectual property (IP), even though their research is largely funded by taxpayers. In the United States, the passage of the 1980 Bayh-Dole Act enabled US universities to retain ownership of the products of federally funded research that had previously been non-exclusively licensed to anyone on request ${ }^{4}$.

Broad patents covering the 'building blocks' of nanotechnology - such as quantum dots, nanowires and fullerenes, carbon nanotubes and methods for making them - hamper conscientious innovators, who must spend time and money to acquire all the necessary licences to avoid lawsuits ${ }^{5}$.

Examples of patents that cover basic components include one owned by the multinational chip manufacturer Intel, which covers a method for making almost any nanostructure with a diameter less than $50 \mathrm{~nm}$; another, held by nanotechnology company NanoSys of Palo Alto, California, covers composites consisting of a matrix and any form of nanostructure. And Rice University in Houston, Texas, has a patent covering "composition of matter comprising at least about $99 \%$ by weight of fullerene nanotubes".

The vast majority of publicly announced IP licence agreements are now exclusive, meaning that only a single person or entity may use the technology or any other technology dependent on it $^{6}$. This cripples competition and technological development, because all other would-be innovators are shut out of the market. Exclusive licence agreements for building-block patents can restrict entire swathes of future innovation.

An evaluation of the carbon-nanotube patent thicket in 2006 found that of 446 carbon-nanotube patents issued in the United States, in which 8,557 claims were made, 420 of those claims were of a building-block

"Stopping
patents
on basic
nanotechnology
will create
much more
innovation."
type ${ }^{7}$. Imagine how equivalent patenting of the idea of a semiconductor or basic programming would have stifled electronics and computing.

These dense webs of overlapping rights are created partly as a result of the complex nature of the underlying science. Beating into this patent thicket is made difficult for innovators and patent examiners alike because of the field's interdisciplinary nature and its span across a range of industries. Nanoscience uses a rich and fast-evolving lexicon of technical language - carbon nanotubes can, for example, be described as nanofibres, fibrils, shells, nanocylinders, buckytubes or nanowires. For nanotechnology patent examiners at the USPTO, incomplete availability of information and inadequate training are recognized problems ${ }^{8}$.

Licences can be costly, but the potential expense of litigation for not acquiring them is often much greater. Multimillion-dollar legal fees have overwhelmed nanotechnology companies such as Evident Technologies (legal fees of $\$ 1$ million compared with $\$ 4$ million in assets) and Luna Innovations (ordered by a jury to pay $\$ 36$ million despite assets of $\$ 20$ million). Such risks dissuade other companies from working in the nanotechnology field.

\section{THE OPEN-SOURCE ALTERNATIVE}

This IP rush assumes that a financial incentive is necessary to innovate, and that without the market exclusivity (monopoly) offered by a patent, development of commercially viable products will be hampered. But there is another way, as decades of innovation for free and open-source software show. Large Internet-based companies such as Google and Facebook use this type of software. Others, such as Red Hat, make more than $\$ 1$ billion a year from selling services for products that they give away for free, like Red Hat's version of the computer operating system Linux.

An open-source model would leave nanotechnology companies free to use the best tools, materials and devices available. Costs would be cut because most licence fees would no longer be necessary. Without the shelter of an IP monopoly, innovation would be a necessity for a company to survive. Openness reduces the barrier for small, nimble entities entering the market.

The field of nanotechnology is a combination of information (such as chemical formulae), software (for example, modelling tools) and hardware (such as atomic force microscopes). All three areas can adopt open-source principles, and some steps have already been taken towards this.

The nanoHUB.org website - established in 2002 by the Network for Computational Nanotechnology with funding from the US National Science Foundation (NSF) - shares simulation programs based on open-source software for nanotechnology research as well as educational materials. Its content is used by hundreds of universities worldwide. Other types of free and open-source software, from microscope-control programs to molecular modelling tools, are proliferating.

Also following an open-source approach are programmes to share construction plans for large and expensive proprietary items of scientific equipment. For example, the SXM team at the University of Münster, Germany, provides free instructions for building a scanning tunnelling microscope. The team has reserved the right to sell the machine, but the list of materials, circuit diagrams and full instructions are posted online (sxm4.uni-muenster.de) so that anyone can build one. The university hosts a spin-off company that makes money by providing add-on services including analytics and workshops.

Critics might counter that the hardware and materials on which most nanotechnology companies base their products are fundamentally different from software, so an open nanotechnology industry would have difficulty attracting the capital needed to scale up. They argue that leading open-source hardware companies - Adafruit, BeagleBoard, Chumby, Liquidware, Seeed Studio and SparkFun Electronics - are small, new firms testing unproven business models.

Yet these and dozens of other companies, including Arduino, MakerShed and Solarbotics, earn millions of dollars in revenue each year through providing and

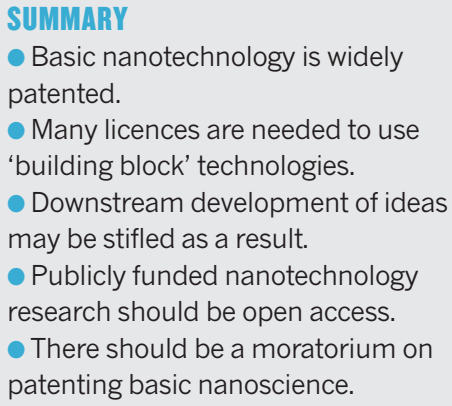




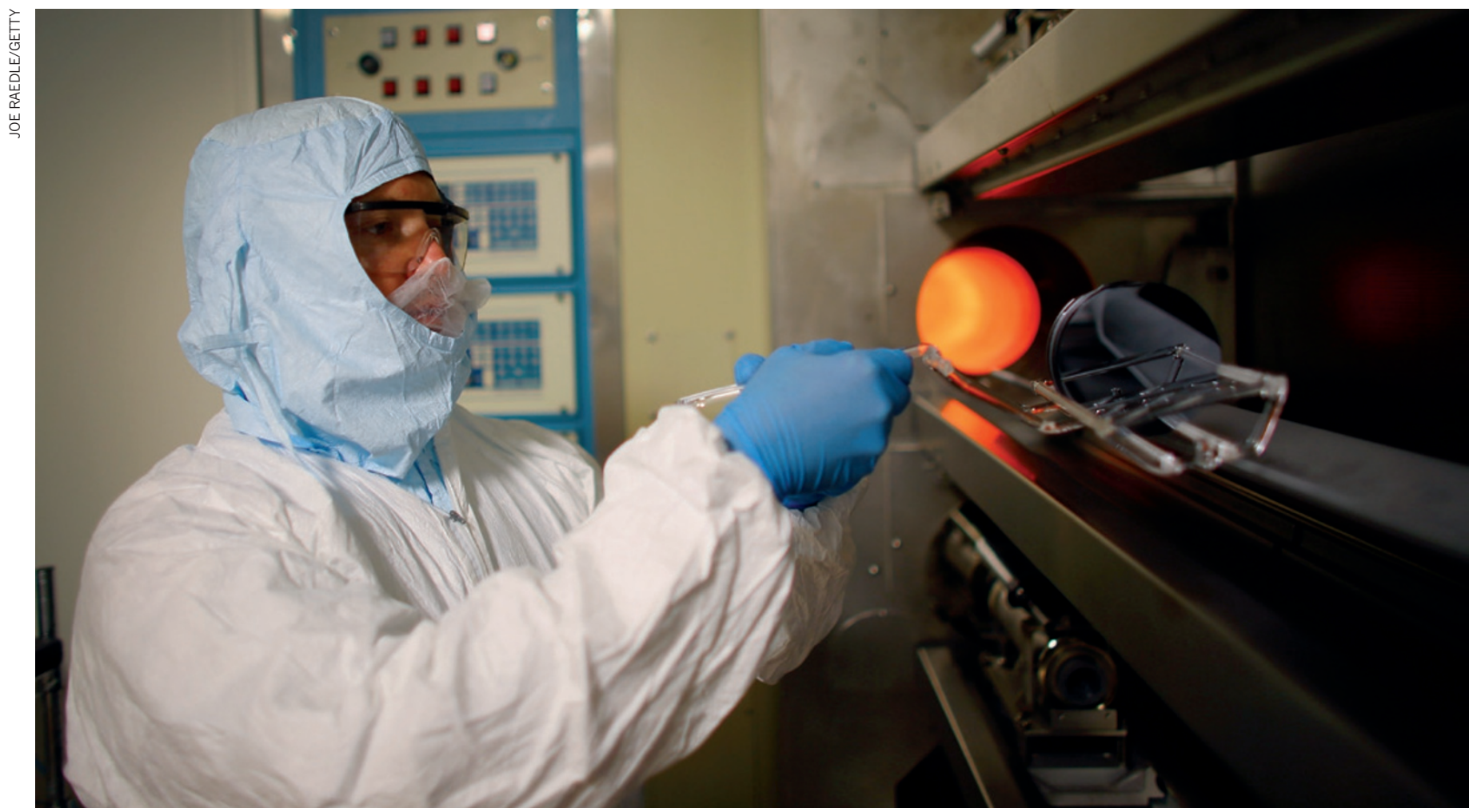

A nanotechnology researcher at a diffusion furnace handles silicon wafers used in integrated circuits.

supporting open-source hardware in other technological areas. Arduino's open-source microcontroller, for example, has been adopted by thousands of projects, including three-dimensional printing and additive layer manufacturing. These printers are in turn used to fabricate research tools in nanotechnology and other disciplines ${ }^{9}$, spearheading a cascade of innovation that The Economist has identified as leading to the "third industrial revolution".

\section{A PATH FORWARD}

Stopping patents on basic nanotechnology will create much more innovation than there is now. Three steps are needed. First, the NSF and funding agencies in other countries must insist that the taxpaying public pays only once. Published results from all publicly funded nanotechnology research should be made freely available on the Internet, following established open-access protocols and using databases such as arXiv.

For nanotechnology research in the United States, the NSF should adopt a public-access policy similar to that of the National Institutes of Health (NIH), which stipulates that all NIH-funded research is made freely and openly available on acceptance for publication. The foundation should also support funding for author-pays publishing. In the longer term, Congress should alter the Bayh-Dole Act to exclude private IP lockdown of publicly funded innovations.

Open access to the documentation for publicly funded nanotechnology research would reduce overly broad patenting by ensuring that patent examiners and innovators have access to more of the literature. It would also expand commercial activity by providing more academics and companies with up-to-date information. Bringing more public oversight to nanotechnology projects could also help to allay fears of the potential negative effects of nanotechnology ${ }^{10}$.

Second, all publicly funded ideas and innovations in the nanotechnology sector should not be patented; instead, they should stay in the public domain. These ideas could be deposited in journals or on sites such as nanoHUB.

Third, the USPTO should issue a moratorium on patenting nanotechnology-related fundamental science, materials and concepts. Simply identifying a new behaviour of a material at the nanoscale should not be enough to claim a patent that stops others from working with that material. The current US patent law must be enforced much more strictly.

Companies and universities could still patent applied nanotechnology innovations for which they can garner private investment. Even if universities' licence revenue for fundamental science disappeared, it is far outweighed by the payments for research overheads that come from federally funded grants, often at rates of more than $50 \%$ of grant income. For example, at my own institution, which attracts one-and-a-half times the national average of licence agreements per dollar of research, the total grant income exceeds that from licensing by more than 100 times. Individual researchers rarely benefit in any significant way from licence royalties.

These three changes to the requirements of publicly funded research and patent interpretations in nanotechnology would ensure an innovative market, and leverage the best value for taxpayers from their research investments.

Joshua M. Pearce is associate professor in the Open Sustainability Technology Lab, Departments of Materials Science \& Engineering and of Electrical \& Computer Engineering, Michigan Technological University, Houghton, Michigan 499311295, USA.

e-mail:pearce@mtu.edu

1. Miller, J. C., Serrato, R. M., Represas-Cardenas, J. M. \& Kundahl, G. A. The Handbook Of Nanotechnology: Business, Policy, and Intellectual Property Law (John Wiley \& Sons, 2005).

2. Lemley, M. A. Stanford Law Review 58, 601-630 (2005).

3. Mushtaq, U. \& Pearce, J. M. in Nanotechnology and Global Sustainability (eds Maclurcan, D. \& Radywyl, N.) 191-213 (CRC, 2011).

4. Makker, A. Southern California Law Review $\mathbf{8 4}$ 1163-1203 (2011)

5. Heller, M. A. \& Eisenberg, R. S. Science 280, 698-701 (1998).

6. Tullis, T. K. Nanotechnology Review 1, 189-205 (2012).

7. Harris, D. L. in Nanotechnology \& Society (eds Allhoff, F. \& Lin, P.) 163-184 (Springer, 2009).

8. Stiles, A. R. Drexel Law Review 4, 555-592 (2012).

9. Pearce, J. M. Science 337, 1303-1304 (2012).

10.Toumey, C. Nature Nanotechnol. 4, 136-137 (2009). 